\title{
Statement about ownership and other particulars of Resonance - journal of science education
}

1. Place of Publication :

2. Periodicity of Publication :

3. Printer's Name :

4. and 5. Publisher and Editor :

6. Nationality :

7. Address :

8. Name and Address of the Owner :
Bangalore

Monthly

R Ramaswamy

Indian Academy of Sciences

Bangalore 560080

R Ramaswamy

Indian

Indian Academy of Sciences

P.B. No. 8005, Bangalore 560080

Indian Academy of Sciences

Bangalore 560080

I, R Ramaswamy, hereby declare that the particulars given above are true to the best of my knowledge.

Date: 1st March 2013

R Ramaswamy

Signature of Publisher 